\title{
ORALIDADE \\ EM CONTEXTO \\ ACADÊMICO: \\ AS CONFIGURAÇÕES \\ DO GÊNERO \\ ENTREVISTA \\ DE ESPECIALISTA \\ NA FORMAÇÃO \\ DOCENTE
}

\section{ORALIDAD EN UN CONTEXTO ACADÉMICO: LASCONFIGURACIONES DEL GÉNERO ENTREVISTA AL ESPECIALISTA EN LA FORMACIÓN DOCENTE}

ORALITY IN ACADEMIC CONTEXT: THE CONFIGURATIONS OF THE GENRE EXPERTISE INTERVIEW IN TEACHING EDUCATION

Daniela Silva Vieira*

Tania Guedes Magalhães** Universidade Federal de Juiz de Fora

RESUMO: Este trabalho apresenta um modelo didático do gênero oral entrevista de especialista de contexto acadêmico, construído em um curso de formação inicial e continuada docente. Com base na perspectiva da didática das línguas, procedemos a um levantamento das configurações deste gênero utilizando os pressupostos de análise do Interacionismo Sociodiscursivo, a partir de

\footnotetext{
* Doutora em Linguística Aplicada pela UFRJ, é professora da Faculdade de Letras da UFjF. Integrante do Grupo de Pesquisa "Linguagem, Ensino e Práticas sociais", desenvolveu estágio pós-doutoral no Programa de Pós-Graduaça em EducaçãodaUFJF.E-mail:daniela.vieira40@yahoo.com.br.

** Doutora em Letras - Estudos Linguísticos pela UFF, é professora do Programa de Pós-Graduação em Educação da UFJF, atuando na linha "Linguagens, culturas e saberes". Atua na graduaça com os cursos de Letras e Pedagogia e coordena o Grupode Pesquisa “Linguagem, Ensinoe Práticassociais”. E-mail: tania.magalhaes95@gmail.com.
} 
um corpus de entrevistas com especialistas do campo da Educação e da Linguística Aplicada, levando em consideração a situação de difusão de conhecimento científico. O modelo didático subsidiou duas ações: a) o estudo do gênero para a produção de entrevistas de especialista pelos cursistas; e b) a elaboração de materiais didáticos para o trabalho com a oralidade na escola. Percebe-se a potencialidade do modelo didático na formação, na criação de práticas que não apenas traga reflexões sobre a transposição de gêneros orais para o ensino básico, mas que propicie ao docente uma postura ativa de produção e circulação de linguagem.

PALAVRAS-CHAVE: Oralidade. Modelo Didático de Gênero. Entrevista de especialista.

RESUMEN: Este trabajo presenta un modelo didáctico de la entrevista oral al especialista en género de un contexto académico, construido a partir de un curso de formación inicial y continuada docente. En función de la perspectiva de la didáctica de los lenguajes, procedemos a un levantamiento de lasconfiguraciones de este género utilizando los supuestos de análisis del Interaccionismo Sociodiscursivo, a partir de un corpus de entrevistas a especialistas en el campo de la Educación y la Lingüística Aplicada, teniendo en cuenta la situación de difusión del conocimiento científico. El modelo didácticoapoyó dos acciones: a) el estudio de género para la producción de entrevistas por parte de los participantes del curso; y b) la elaboración de materialesdidácticos para trabajar con la oralidad en la escuela. Se percibe el potencial del modelo didáctico en la formación, en la creación de prácticas que no solo aportan reflexiones sobre la transposición de los géneros orales a la educación básica, sino que permita al docente una postura activa de producción y circulación del lenguaje.

PALABRAS CLAVE: Oralidad. Modelo didáctico de género. Entrevista al especialista.

ABSTRACT: This work presents a didactic model of the genre expertise interview in academic context. It was created within a course designed to initial training and continuing education for teaching professionals. Based on the perspective the didatics of languages we list the configurations of the genre by using the analysing framework of SociodiscoursiveInteracionism and we analyze a set of expertise interviews from education and Applied Linguistics area considereng its social function of sharing cientificknowlwege. That didactic model suported two actions: $a$ ) the study of the genre which allowed a production of interviews by the students and b) the production of didatic material for learning orality in classroom. It was seen the didactic model becomes a powerful tool to enhance practices which not only brings reflections to the usage and application of oral genres to elementary school, but it lets the teacher be active on the process of creation and circulation of the language as well.

KEYWORDS: Orality. Didactic model of genre. Expertise interview.

\section{INTRODUÇÃO}

Nas pesquisas realizadas nas últimas décadas que tematizam o eixo da oralidade, percebemos que ainda é pouco enfocado nas escolas, mas necessário, um trabalho sistemático para o desenvolvimento de capacidades de linguagem que incida tanto na compreensão (escuta) e na produção oral, quanto na análise linguística de diferentes gêneros orais em situações de comunicação em diversos contextos. A importância do desenvolvimento de uma efetiva pedagogia do oral envolve o ensino e a reflexão sobre os aspectos da modalidade falada de forma consciente, com vistas a um agir dos estudantes pela linguagem em sociedade, como defendem diferentes autores (MARCUSCHI, 1997; SCHNEUWLY; DOLZ, 2004; FÁVERO; ANDRADE; AQUINO, 2005; LEAL; GOIS, 2012; BUENO; COSTA-HÜBES, 2015; ARAÚJO; SILVA, 2016; MAGALHÃES; CRISTOVÃO, 2018).

Todavia, para que na escola tenhamos um trabalho consistente de desenvolvimento de capacidades de linguagem, a formação docente precisa se voltar para a compreensão dos gêneros orais como objetos de ensino, considerando uma concepção de linguagem como interação social, para que haja propostas relevantes nas quais os licenciandos e professores, em formação continuada, não só interajam por gêneros em práticas sociais, mas também reflitam conscientemente sobre elas. Nessa perspectiva, não basta que os graduandos e os docentes se apropriem de conhecimentos disciplinares e pedagógicos sobre a oralidade e os gêneros orais, mas também vemos a necessidade de que sejam inseridos em atividades de linguagem acadêmicas e profissionais (orais e escritas) na licenciatura e na formação continuada, perspectiva à qual temos nos filiado em atividades de pesquisa, ensino e extensão no âmbito do Grupo de Pesquisa Linguagem, Ensino e Práticas Sociais, ao qual nos vinculamos. Nesse sentido, temos envidado esforços para que nossos cursos envolvam não apenas uma discussão sobre conhecimentos disciplinares (a língua portuguesa, os gêneros, os letramentos), conhecimentos pedagógicos (aprendizagem, transposição didática, currículos, materiais didáticos, avaliação da 
aprendizagem) e conhecimentos profissionais (o agir didático, as diferentes dimensões do trabalho docente, etc), mas também coloquem os docentes em situações de interação pelos gêneros orais e escritos, de forma integrada, em atividades coletivas de linguagem, com vistas a uma reflexão sobre essas produções que contribua para a construção de conhecimentos pedagógicos que propiciem modificações no seu agir didático a partir da própria experiência de autoria.

Nessa direção, este trabalho, que se situa numa investigação mais ampla de produção e análise de materiais didático em um curso ${ }^{1}$ de formação docente sobre oralidade na escola básica, tem como objetivo analisar as dimensões ensináveis do gênero ${ }^{2}$ entrevista de especialista, um subgênero da entrevista, em contexto acadêmico, a partir da perspectiva do Interacionismo Sociodiscursivo (ISD) para a construção de modelos didáticos de gêneros (MDG). Esta pesquisa, que envolve um levantamento das configurações do gênero, foi realizada em um curso de extensão ${ }^{3}$, em que os docentes vivenciaram não apenas aprendizagem relativas a discussões teórico-conceituais do campo da oralidade e dos gêneros orais, mas também foram convidados a produzir o gênero para um canal do YouTube.

A escolha pelo gênero oral entrevista de especialista, que circula em contexto acadêmico de divulgação ou comunicação científica ${ }^{4}$, se deu uma vez que as pesquisas no campo do letramento acadêmico incidem fortemente em análises e didatização de gêneros da escrita como artigos, resenhas, resumos, monografias, dissertações. No eixo da oralidade, assim como acontece na escola, há menos pesquisas (SITRI, 2015; ZANI; BUENO, 2017; MAGALHÃES, 2018; ABREU-TARDELLI; VOLTERO, 2019), o que vem sendo estudado no nosso grupo de pesquisa, com vistas a reverter este quadro.

Nesse sentido, para que o curso de formação pudesse criar uma situação relevante de aprendizagem do gênero, apropriação, produção e circulação, elaboramos um modelo didático de gênero entrevista de especialista, foco deste artigo, um gênero de divulgação científica em que um acadêmico especialista em determinada temática é entrevistado por canais e emissoras universitárias ou de instituições ligadas à educação para tratar de temática pertinente ao campo, no nosso caso no ensino de Língua Portuguesa na educação básica. Trata-se então de um gênero que mescla características das esferas acadêmica e jornalística, respectivamente por se ancorarem em resultados das atividades da pesquisa científica, e por englobar ações de coleta, tratamento e divulgação desses resultados e seus impactos sociais (conforme nota de rodapé 5).

Partindo deste panorama, nosso artigo está organizado da seguinte forma: após esta introdução, construímos três seções - a formação docente, aspectos da didática das línguas e do modelo didático de gênero e, por fim, a entrevista. Em seguida, traçamos os caminhos metodológicos do trabalho, fornecendo informações da pesquisa mais ampla e do curso de extensão. Após apresentar as configurações do gênero enfocado, trazemos breves encaminhamentos sobre a importância deste instrumento nas pesquisas no campo da Educação e da Linguística Aplicada ao ensino de língua materna, numa perspectiva dos letramentos como prática social, e à formação de professores.

\footnotetext{
${ }^{1}$ Informações sobre o curso serão fornecidas na metodologia. Abordamos, neste artigo, a construção do MDG, um instrumento potencial para as etapas subsequentes do trabalho do professor, como a elaboração de sequências didáticas, exercícios diversificados e materiais didáticos, que não enfocamos aqui.

${ }^{2} \mathrm{Na}$ seção 4, abordamos essa classificação de acordo com Hoffnagel (2003) e Marcuschi (2008). Apesar de este tipo de entrevista ser um subgênero da entrevista, conforme os autores, usaremos, neste artigo, a denominação "gênero" entrevista de especialista, uma vez que fica clara essa relação.

${ }^{3}$ A pesquisa-ação envolveu a análise das produções orais e das sessões reflexivas realizadas em um curso de extensão, cujos resultados abordaremos em outro trabalho. Na referida pesquisa, buscamos analisar de que modo os docentes avaliam as experiências de autoria (produzindo as entrevistas com especialistas, tutoriais e materiais didáticos) e seus impactos na prática profissional futura.

${ }^{4}$ Segundo Albagli (1996), "Divulgação científica pode ser definida como 'o uso de processos e recursos técnicos para a comunicação da informação científica e tecnológica ao público em geral'. Divulgação científica é um conceito mais restrito do que difusão científica e um conceito mais amplo do que comunicação científica. Difusão científica refere-se a 'todo e qualquer processo usado para a comunicação da informação científica e tecnológica'. Ou seja, a difusão científica pode ser orientada tanto para especialistas (neste caso, é sinônimo de disseminação científica), quanto para o público leigo em geral (aqui tem o mesmo significado de divulgação). Já comunicação da ciência e tecnologia significa 'comunicação de informação científica e tecnológica, transcrita em códigos especializados, para um público seleto formado de especialistas" (ALBAGLI, 1996, p. 396).
} 


\section{A FORMAÇÃO DOCENTE EM CONTEXTO ACADÊMICO E PROFISSIONAL PARA O TRABALHO COM A ORALIDADE}

Uma lacuna indicada nas pesquisas de Luna (2017) é que, apesar de detectar avanços no que tange à inserção da temática da oralidade, gêneros orais e relações fala-escrita nos cursos de formação inicial em Letras, a discussão sobre as questões "práticas", referente ao campo pedagógico e ao trabalho docente, ainda não são suficientemente abordadas. Em relação a isso, vemos uma necessidade de que as licenciaturas contemplem uma discussão conceitual e pedagógica no eixo da oralidade. Tal formação precisa ultrapassar a conceituação no que tange à oralidade, gêneros orais e fala e propor um exercício reflexivo de apropriação de conhecimentos sobre a transposição dos gêneros orais para a escola, envolvendo os documentos oficiais da educação, a elaboração de materiais, a análise de livros didáticos diversificados, amplas e densas discussões sobre práticas docentes, como os estudos de caso e relatos de experiência, proposição de princípios específicos sobre a avaliação dos gêneros orais, dentre outros; deve considerar, sobretudo, uma concepção de oralidade como prática social integrada à escrita (ROJO; SCHNEUWLY, 2006), que rompe com a crença histórica e dicotômica de supremacia da escrita (MARCUSCHI, 2001).

Em diferentes pesquisas, são constatados alguns resultados preocupantes sobre as ações desenvolvidas em cursos de formação docente, no tocante aos letramentos acadêmico e profissional ${ }^{5}$ : a) falta de oportunidades de vivenciar práticas profissionais na graduação (BUENO, 2009; GATTI et al., 2019; VIANNA et al., 2016) ; (b) lacunas na sistematização dos gêneros envolvidos no letramento acadêmico, orais e escritos (ARAÚJO, SILVA, 2016; ZANI, BUENO, 2017; ABREU-TARDELLI, VOLTERO, 2019); c) falta de reflexão sistemática sobre essas práticas de letramento acadêmico e profissional docente (LOPES, 2018; SITRI, RINCK; 2015); d) necessidade de ressignificação da formação inicial e continuada, de maneira que possamos ampliar interação pela linguagem em contexto acadêmico e profissional, a exemplo do que tem sido feito em várias pesquisas (GUEDES-PINTO, 2012; MACHADO; LOUSADA; FERREIRA, 2011; GUIMARÃES; CARNIN; BICALHO, 2016; CARNIN, 2020).

Em uma das pesquisas realizadas em nosso grupo (MAGALHÃES; CALLIAN; CABETTE; 2020), percebemos que as profissionais do Ensino Fundamental, no trabalho docente, realizam uma série de tarefas fora da sala de aula, por meio de uma gama de gêneros de texto, para as quais não são formadas; elas afirmam que os cursos de formação não indicam que há essas variadas tarefas, e os estágios são insuficientes para inserir os graduandos em produções orais e escritas, visto que frequentemente enfocam a sala de aula e o agir didático; além disso, há pouca (ou nenhuma) reflexão e problematização sobre a inserção nessas práticas orais e escritas, como realizar reuniões, fazer orientação de alunos de estágio, realizar campanhas da área de saúde, participar de assembleias, ministrar palestras em cursos de formação docente, produzir uma série de relatórios, dentre outros.

Ademais, no que tange ao letramento acadêmico, também há um conjunto amplo de gêneros orais pelos quais os graduandos e docentes interagem que não são sistematizados e ensinados, e talvez não haja sequer reflexões sobre essas práticas. Nesse caso, precisamos considerar que letramento acadêmico e profissional são dimensões transversais, e não dicotômicas, da formação docente (VIANA et al., 2016). Essa ideia reforça a defesa de que é necessário inserir na formação inicial e continuada uma série de atividades de linguagem e gêneros ainda não estudados, como aqueles típicos do contexto acadêmico e profissional ${ }^{6}$. Assim como Magalhães (2012, p. 9) afirma, "letramento é diversificado, plural, organizado em gêneros discursivos particulares, e isso precisa ser lembrado no processo de formação de professores. Os gêneros selecionados para o trabalho em sala de aula vão depender das demandas do grupo particular e de sua realidade cultural.", assim como concordam diferentes pesquisadores.

\footnotetext{
${ }^{5}$ Consideramos letramento acadêmico segundo Fiad (2015, 2015, p.26): para a autora, letramento acadêmico constitui um conjunto de práticas de escrita que propiciam um "[...] olhar crítico e questionador para os eventos e práticas de letramento não só no contexto universitário, mas para o contexto acadêmico entendido de modo mais amplo, envolvendo, por exemplo, publicações em periódicos científicos e eventos científicos como conferências e congressos". Para letramento profissional, tomamos as considerações de Costa e Paz (2017, p. 205): "[...] é possível considerar que as práticas de linguagem que emergem em situações de trabalho [...] devem ser consideradas como linguagem laboral ou profissional". No nosso caso, o letramento profissional docente privilegia o contexto escolar, que envolve uma série de práticas dentro e fora da sala de aula. Em ambas as perspectivas, as autoras baseiam-se na a multiplicidade das práticas letradas articuladas aos diversos papéis sociais dos sujeitos em contextos sócio-históricos específicos (STREET, 2014).

6 "Um breve levantamento mostra que há variados gêneros pelos quais os estudantes e docentes interagem no contexto acadêmico e profissional, que podem ser objeto de análise a partir das vivências, como seminários, palestras, conferências, minicurso, defesas, comunicação oral, relato de experiência, debate eleitoral, apresentação de banner/pôster, produção de vídeos como documentário, tutorial, vídeo de divulgação científica (para disciplinas e feiras de iniciação científica das universidades), reuniões (de diretório acadêmico, colegiados, departamento), fóruns deliberativos, rodas de conversa, entrevistas de seleção (de emprego, de bolsistas de projetos diversificados), apresentação pessoal, dentre outros" (MAGALHÃES, 2020, p. 76)
} 
A partir das lacunas identificadas nos cursos de formação relativas à pouca frequência da temática da oralidade, projetos têm sido desenvolvidos em iniciativas que a abordam não apenas na sua vertente teórico-conceitual, mas também nas essenciais questões da transposição didática (LEAL; GOIS, 2012; BUENO; COSTA-HÜBES, 2015; ARAÚJO; SILVA, 2016; MAGALHÃES, 2018; DOLZ; SILVA-HARDMEYER; COPOLLA, 2018; OLIVEIRA; COSTA-MACIEL, 2018; SCHNEIDER, 2019; dentre outros). Esses projetos mostram como é possível construir com os docentes um agir didático que viabilize o ensino sistematizado da fala, assim como da escrita, possibilitando ao estudante da escola básica participar de eventos variados e problematizar o uso de diferentes gêneros em contextos da interação.

Para além de considerar que as formações têm avançado em questões sobre oralidade que repercutem na escola básica de forma positiva, como as citadas acima, mesmo que pareçam ser ainda iniciativas isoladas, uma concepção que tem nos levado a repensar nossas práticas formativas é a que considera a apropriação da linguagem como fator central do desenvolvimento humano (BRONCKART, 2006). Isso resulta em atividades em que os graduandos e os docentes são inseridos em situações de interação pela linguagem tanto do contexto acadêmico quanto do profissional. Há vários exemplos deste tipo de ação que trazem estratégias de ensino calcadas em dimensões da oralidade e dos letramentos; trago a experiência de Souza e Cristovão (2015), que realizaram pesquisa para analisar o desempenho dos graduandos de Língua Inglesa em entrevistas de emprego para escolas de idiomas, considerando que a imersão dos estudantes em gêneros típicos da esfera do trabalho é fundamental para a visibilização e melhoria do próprio desempenho acadêmico e profissional, além de ampliar os conhecimentos sobre o trabalho docente. Outro exemplo é a pesquisa de Carnin (2020), que se baseia na concepção de homologia de processos: o trabalho indica que a inserção do educador em formação continuada em atividades semelhantes ao que pretende propor aos alunos, bem como a reflexão sobre tais atividades, pode propiciar um ensino de gêneros mais eficaz e consciente, ampliando conhecimentos sobre transposição didática. Ambas as investigações mostram que a apropriação dos gêneros pelos graduandos e docentes pode ser um instrumento potencial de desenvolvimento.

É nessa direção que consideramos as entrevistas de especialista um importante instrumento de divulgação e construção de conhecimento científico na formação docente, bastante utilizada nas aulas, mas um gênero ainda pouco estudado neste contexto. Assim, a construção de um modelo didático da entrevista desta esfera é essencial para a didatização (na universidade ou na escola), constituindo-se como um subsídio prático para nosso curso de extensão. Embora a entrevista de especialista esteja muito presente em aulas da graduação, por exemplo, acreditamos que haja ênfase nos conteúdos teórico-conceituais e pouca reflexão sobre a entrevista como prática discursiva científica, como fizemos nas etapas de nosso curso. Por ser o MDG um instrumento de trabalho do professor, abordaremos esta temática na seção seguinte.

\section{A DIDÁTICA DAS LÍNGUAS E O MODELO DIDÁTICO DE GÊNERO}

O Interacionismo Sociodiscursivo intitula-se como uma ciência do humano (BRONCKART, 2006) por seu caráter transdisciplinar que congrega aportes teóricos e metodológicos de diferentes campos do conhecimento. Tal perspectiva compreende que a linguagem é fundamental para a manutenção das interações sociais e responsável por veicular as diferentes significações das ações e dos pré-construídos coletivos. Assim, a linguagem é determinante para o desenvolvimento humano, visto que o processo de socialização pela linguagem se dá a partir de suas condições sociais e históricas, e a imersão do ser humano em atividades sociais leva-os a compreender e se apropriar de esquemas e pré-construídos, por exemplo os gêneros de texto.

Para o ISD, "as práticas linguageiras situadas (ou os textos-discursos) são os instrumentos principais do desenvolvimento humano, tanto em relação aos conhecimentos e aos saberes, quanto em relação às capacidades do agir e da identidade das pessoas" (BRONCKART, 2006, p. 10). É por isso que o conceito de gênero é central, porque sua apropriação possibilita a participação em atividades coletivas diversificadas. Em qualquer contexto, “[...] o gênero adotado para realizar a ação de linguagem deverá ser eficaz em relação ao objetivo visado, deverá ser apropriado aos valores do lugar social implicado e aos papéis que este gera e, enfim, deverá contribuir para promover a 'imagem de si' que o agente submete à avaliação social de sua ação” (BRONCKART, 1999, p. 102). 
Considerando a vertente da didática das línguas, quando se apropria dos gêneros de texto, há mais que a aprendizagem de conceitos linguísticos: o agir pela linguagem requer a compreensão de valores sociais e culturais das atividades coletivas. Em relação ao desenvolvimento da identidade, Bronckart esclarece que "[...] é no processo geral de apropriação dos gêneros que se molda a pessoa humana" (1999, p. 103); isso porque a interação pelos gêneros em diferentes atividades (jornalísticas, acadêmicas, literárias, científicas, profissionais) requer apropriação de ações pelo sujeito, o que constitui a sua identidade nesses contextos. No nosso caso, a apropriação do gênero entrevista de especialista envolve uma reflexão sobre características do contexto acadêmico e de divulgação científica; inserir os cursistas nesta produção possibilita a familiarização com formas de construção e circulação de conhecimento, bem como a sensibilização para uma concepção de linguagem como interação, o que impactará, possivelmente, o trabalho com os gêneros em contexto escolar.

Dolz, Noverraz e Schneuwly (2004) ressaltam que o trabalho a partir dos gêneros propicia uma reconstrução das práticas de linguagem através da interação de três fatores: as especificidades das práticas de linguagem; as estratégias de ensino em intervenções desenvolvidas para aprendizagem dos gêneros inseridos em situações de comunicação; e as capacidades de linguagem, desenvolvidas pelos alunos em situações de interação específicas.

Em relação à aprendizagem, é preciso fazer uma sistematização das características a serem abordadas no desenvolvimento de sequências didáticas (ou outras propostas de organização do trabalho pedagógico, como projetos didáticos de gêneros, projetos de leitura e escrita etc). Para que sejam produzidas diferentes tarefas, é necessária a elaboração de um modelo didático de gênero, um levantamento de suas configurações a partir de um corpus. Segundo Strukosk, Biazi e Stutz,

A designação modelo didático de gênero tem sua origem na engenharia didática, cujo propósito principal visa desenvolver uma compreensão profunda sobre o funcionamento do gênero que, por sua vez, serve de apoio para a construção de material didático e para fortalecer a prática de professores de línguas. Esse instrumento revela as características do gênero textual escolhido, mediante a descrição das dimensões que o compõe e que possibilita a sistematização de atividades didáticas pertinentes às situações de comunicação abordadas em sala de aula. (STRUKOSK, BIAZI; STUTZ, 2017, p. 156)

Magalhães e Cristóvão (2018) ressaltam a importância do MDG tanto na formação quanto na prática docente, uma vez que

[...] trata-se de uma pesquisa feita pelo professor previamente à intervenção na sala de aula, num verdadeiro levantamento e constituição de corpus para análise das dimensões ensináveis de um gênero, de modo que o aluno tanto vivencie a prática social que constitui o gênero como estude as operações de linguagem necessárias para agir por meio dele. A modelização explicita o conhecimento implícito de um gênero. (MAGALHÃES, CRISTÓVÃO, 2018, p.31-32)

O MDG revela as “relações entre os gêneros de referência e a adaptação destes últimos para o ensino” (DE PIETRO; SCHNEUWLY, 2014, p.53). Os autores alertam que a modelização não deve cair numa normalização de passos a serem seguidos; os modelos devem manter um certo nível de abstração, que não impeça de serem incluídas novas operações. Em suma, uma modelização é uma ação imprescindível, já que "[...] todo ato de ensino implica sempre uma explicação mínima dos elementos ensinados, uma escolha de certas dimensões em relação a outras não tratadas" (2014, p.72). Alguns elementos são fundamentais: corpus de textos do gênero a ser ensinado, análise desses textos incluindo as variações do gênero; seleção de dimensões para o ensino considerando questões didáticas. Os pesquisadores afirmam que o modelo didático é construído a partir de quatro conjuntos de dados ou fontes: as práticas sociais de referência; a literatura sobre o gênero; as práticas de linguagem dos alunos e as práticas escolares.

Machado e Cristóvão (2006) destacam que a construção de um MDG, embora contemple elementos característicos e típicos de textos que pertencem ao gênero a ser ensinado, não constitui um modelo fixo, mas considera a flexibilização de diferentes referências teóricas sobre o gênero, a partir das observações e análises das práticas sociais que o envolve. Essa visão do que é "relativamente 
estável"7 nos gêneros leva o aluno a uma postura mais crítica porque há uma compreensão da variação, com configurações relativas aos contextos e às atividades em que se ancoram. Os elementos básicos, segundo as autoras, conforme o modelo de análise de textos do ISD da arquitetura textual, envolvem:

\begin{abstract}
a) as características da situação de produção (quem é o emissor, em que papel social se encontra, a quem se dirige, em que papel se encontra o receptor, em que local é produzido, em qual instituição social se produz e circula, em que momento, em qual suporte, com qual objetivo, em que tipo de linguagem, qual é a atividade não verbal a que se relaciona, qual o valor social que lhe é atribuído etc.); b) os conteúdos típicos do gênero; c) as diferentes formas de mobilizar esses conteúdos; d) a construção composicional característica do gênero, ou seja, o plano global mais comum que organiza seus conteúdos; e) o seu estilo particular, ou, em outras palavras: - as configurações específicas de unidades de linguagem que se constituem como traços da posição enunciativa do enunciador: (presença/ausência de pronomes pessoais de primeira e segunda pessoa, dêiticos, tempos verbais, modalizadores, inserção de vozes); - as sequências textuais e os tipos de discurso predominantes e subordinados que caracterizam o gênero; - as características dos mecanismos de coesão nominal e verbal; - as características dos mecanismos de conexão; - as características dos períodos; - as características lexicais. (MACHADO, CRISTÓVÃO, 2006, p.557-558)
\end{abstract}

Entendemos que a modelização é parte fundamental de uma prática pedagógica eficiente. Ressaltamos a necessidade de que os cursos de formação docente possibilitem ao professor conhecer e construir este instrumento que precede as atividades em sala. Vários materiais podem ser construídos com base num MDG e, nesse caso, serão selecionados pelo docente aquelas dimensões que tiverem mais relevância para uma classe específica. Carnin e Guimarães (2018) ressaltam que esse instrumento é tão importante que seria fundamental, inclusive, haver um repositório disponível para docentes ${ }^{8}$, que poderiam então criar seus projetos de ensino. Concordamos com os autores, porque a criação de corpus e a análise desses textos requer um tempo e um instrumental analítico de conceitos científicos da Linguística que, muitas vezes, o professor ainda não tem.

As categorias utilizadas para a construção do modelo de análise da entrevista de especialista são baseadas na perspectiva do ISD. A seguir, apresentamos uma seção cujo tópico é o gênero entrevista de especialista, um dos subgêneros da entrevista.

\title{
4 A ENTREVISTA DE ESPECIALISTA
}

Segundo Baltar (2012), a entrevista é explorada por docentes de diferentes disciplinas; porém, pouco explorada nas aulas de Língua Portuguesa. Como a entrevista é um gênero, segundo o autor, que depende da exposição oral, sistematizada e planejada previamente (com a esquematização de um roteiro, por exemplo), ela tem potencial para diferentes aprendizagens na integração entre fala e escrita.

A entrevista é "[...] uma constelação de eventos possíveis que se realizam como gêneros (ou subgêneros) diversos. Assim, teríamos, por exemplo, entrevista jornalística, entrevista médica, entrevista científica, entrevista de emprego, etc." (HOFFNAGEL, 2003, p. 180). Marcuschi (2008, p. 195) também caracteriza a entrevista como gênero de diferentes modalidades, a partir de uma diversidade de domínios discursivos: entrevista de seleção, de emprego, médica, de especialista, radiofônica, coletiva, científica, de campo, (tele)jornalística, com celebridades, pessoal, enquete etc.

A entrevista de especialista, que Schneuwly e Dolz (2004) descrevem para o contexto radiofônico, é uma modalidade em que há foco num determinado tema de especialidade de um profissional; seu objetivo é ampliar conhecimentos específicos sobre uma determinada área. Os autores afirmam que a entrevista é uma interação autorregulada, cujos participantes são responsáveis pela "[...]

\footnotetext{
${ }^{7}$ Referimo-nos à concepção de Bakhtin (2003, p. 262): “[...] cada campo de utilização da língua elabora seus tipos relativamente estáveis de enunciados, os quais denominamos de gêneros do discurso".

${ }^{8}$ Destacamos o repositório criado pelo Grupo de Estudos e Pesquisas em Linguagem - GEPELin (UNESP/Bauru) que, atendendo a este tipo de demanda, reúne modelos didáticos de gêneros de acesso gratuito.
} 
co-gestão direta, em tempo real, das trocas, apesar da possibilidade de certas manipulações durante a difusão" (SCHNEUWLY; DOLZ, 2004, p. 86). Há um entrevistador, que é um mediador entre o entrevistado e os ouvintes; o mediador está em busca de transmissão de informação para uma população, com restrições mais definidas. Neste caso, ele não se comporta como um jornalista que satisfaz suas curiosidades, mas transmite um saber ao público. Segundo os autores, geralmente os interlocutores "[...] ocupam papéis públicos institucionalizados; a natureza da relação social e interpessoal condiciona fortemente a relação que se instaura entre os dois. Em relação a outros gêneros, a entrevista mantém uma ligação fundamental com o universo da mídia." (SCHNEUWLY; DOLZ, 2004, p. 86). O especialista pode estar sozinho ou pode-se realizar uma entrevista com dois ou três especialistas no tema, para abordar a diversidade do assunto.

No nosso caso, voltamo-nos para as entrevistas feitas com especialistas pesquisadores e professores universitários da área de Linguística Aplicada ao Ensino de Língua Portuguesa e Educação. A especificidade do contexto acadêmico é que queremos particularizar neste artigo, pois trata-se de um gênero ainda pouco abordado. A entrevista de especialista é um dos gêneros do jornalismo científico, que é uma especialidade da divulgação científica e, por esse caráter de divulgação ou comunicação, no contexto universitário parecem ser bastante usadas em sala de aula, como complementares à discussão de artigos científicos na apropriação do conhecimento.

O que situa este tipo de entrevista como prática social pertencente ao campo acadêmico-científico é o papel social de entrevistado (pesquisador reconhecido em uma comunidade e conhecedor profundo de uma temática relevante para a sociedade, em várias áreas do conhecimento), a finalidade (de divulgação do conhecimento científico), o suporte (canais de universidades no YouTube, por exemplo), o contexto de produção (um resultado ruim de avaliações na educação, por exemplo, que gera uma série de entrevistas de especialistas), o conteúdo abordado (resultados de pesquisas, que servem tanto a especialistas quanto a leigos), bem como o contexto de circulação. Os canais universitários, de editoras e programas de divulgação científica são o meio prioritário de circulação desse gênero, como a Canal Futura, a TV USP, Canal do CNPq, da CAPES, só para citar alguns. Há também uma série de canais de divulgação criados no YouTube pelos próprios cientistas, que apesar de “pessoais”, são de popularização da ciência.

Após o isolamento social imposto pela pandemia causada pelo novo coronavírus (SARS-Cov-2) no Brasil, de março de 2020 em diante, algumas instâncias institucionais no interior das universidades, como os grupos de pesquisa, programas de pós-graduação, pró-reitorias das universidades, por exemplo, criaram canais para divulgação de webnários e lives, o que causou até mesmo uma certa "onda" de comunicação e divulgação de conhecimento. Muitos eventos acadêmicos foram realizados em 2020 de forma remota, e esses canais exerceram papel central neste processo.

Para que haja uma sistematização das características da entrevista, como de qualquer gênero oral, além de abordar os elementos como finalidade e interlocutores, os aspectos multimodais são considerados elementos ensináveis, o que é muito negligenciado nas práticas desenvolvidas nas escolas. As autoras Costa-Hübes, Swiderski (2015), Baumgärtner (2015) e Schneider (2019), por exemplo, mostram que, em pesquisa envolvendo elaboração de materiais didáticos por docentes ou licenciandos, os elementos não verbais dos gêneros não são enxergados como aspectos que devem ser ensinados, sendo na maior parte das vezes ignorados nas tarefas elaboradas. Após a intervenção que essas pesquisas propiciaram, percebe-se a multimodalidade dos gêneros e, então, são incluídas análises e reflexões sobre esses elementos.

Dessa forma, aspectos prosódicos, cinésicos e do ambiente, por exemplo, devem ganhar lugar de relevo na análise da oralidade, não de forma transversal e geral, mas como constitutivos de cada gênero (por exemplo, tomada de turno é um fenômeno que acontece de forma diferente nos debates e nas entrevistas). A experiência de Guimarães e Souza (2018), em que questionam "[...] quão interacional é a oralidade que ensinamos na escola”, ressalta que os aspectos não linguísticos devem ser ensinados na interação com a entrevista, como

[...] direcionamento do olhar para o interlocutor, a posição corporal adotada, a possibilidade de alguns gestos acompanharem a fala, até elementos verbais, como a prosódia os marcadores discursivos, os continuadores, etc, enfim, elementos que constroem o engajamento conversacional entre interlocutores. (GUIMARÃES, SOUZA, 2018,p. 97) 
Diferentes experiências com o gênero entrevista, em que são enfocados os aspectos multimodais da oralidade, enfatizam a relevância desse tipo de prática (FÉLIX; BARROS, 2012; BARBOSA; LOPES, 2016; MAGALHÃES; BARBOSA, 2017; ALVIM; MAGALHÃES, 2018; MORATTO; STORTO, 2019). Reafirmamos que para uma prática pedagógica com gêneros orais, é necessário que o professor domine esses conhecimentos, tenha acesso a materiais e descrições de gêneros, sistematize os elementos constitutivos da oralidade e proponha suas práticas.

\section{ASPECTOS METODOLÓGICOS}

A presente pesquisa integra uma investigação mais ampla; uma de nossas ações é analisar os gêneros tutorial em vídeo e entrevista de especialista ${ }^{9}$, para fins de estudo no curso de extensão "Práticas de oralidade no ensino de Língua Portuguesa", ministrado no $2^{\circ}$ semestre de 2020 para graduandos em Letras e Pedagogia, docentes dos anos iniciais do Ensino Fundamental e docentes de Língua Portuguesa dos anos finais do Ensino Fundamental; ambos os grupos (docentes e graduandos), em função do formato online, são oriundos de diferentes cidades brasileiras, num total de 30 cursistas.

O curso envolveu, basicamente, a) conhecimentos teórico-conceituais sobre oralidade, gêneros orais, modalidade falada, supremacia da escrita, continuum fala-escrita, integração oralidade-letramento, multimodalidade, dentre outros; b) conhecimentos pedagógicos: a didatização de gêneros orais; currículo e oralidade; avaliação da oralidade, sequência didática, dentre outros; c) conhecimentos técnicos de tecnologias (programas de filmagem e editoração); d) produção dos gêneros tutoriais (individualmente) ou entrevista (individual ou em dupla) pelos cursistas; e) produção de materiais didáticos; f) reflexão sobre as produções.

Devido ao contexto de pandemia, o curso foi ministrado a distância, pela ferramenta Meet do Google Classroom, com dois encontros síncronos semanais (de $2 \mathrm{~h}$ cada) e assíncronos, num total de 40h. Nos módulos relativos às produções dos gêneros, houve atendimento online individualizado ou em duplas. O curso foi conduzido por três pesquisadoras (duas professoras da UFJF, autoras do artigo, e uma doutoranda do PPGE/UFJF), de outubro a dezembro de 2020. Os participantes foram selecionados por uma lista de inscrição, tendo lugar no curso os 30 primeiros inscritos, a partir da comprovação de docência na escola básica ou matrícula em curso de graduação.

Neste artigo, apresentamos o resultado da análise de 5 entrevistas de especialista, cujos temas se referem a Educação e Linguística Aplicada, visto que usamos frequentemente essas entrevistas para a construção de conhecimentos, pelos docentes e graduandos, sobre Ensino de Língua Portuguesa na escola básica. Trazemos, abaixo, uma breve descrição das entrevistas.

Quadro 1: tema e descrição das entrevistas

\begin{tabular}{c|c} 
Título & Descrição \\
\hline $\begin{array}{c}\text { Como avaliar a estrutura de uma boa } \\
\text { escola (com Wagner Araújo, doutor em } \\
\text { Ciências da Gestão })^{10}\end{array}$ & $\begin{array}{c}\text { Esta entrevista faz parte do programa "Conhecer e aprender" do Amazonas (AM). O objetivo é } \\
\text { debater como os pais podem avaliar os aspectos pedagógicos e estruturais de uma escola, } \\
\text { principalmente para alunos que com necessidades especiais. }\end{array}$ \\
\hline $\begin{array}{c}\text { Especialista fala sobre a BNCC } \\
\text { Sonia Made, Alfaletrar e CENPEC) }\end{array}$ & $\begin{array}{c}\text { A entrevista é produzida para o telejornal da Câmara SP e faz parte de um bloco do jornal. O } \\
\text { objetivo é debater a 3a versão da BNCC e seus impactos no processo de ensino e aprendizagem da } \\
\text { educação básica. }\end{array}$
\end{tabular}

\footnotetext{
${ }^{9}$ A pesquisa envolveu um curso de extensão em que foram enfocados variados gêneros orais, mas dois deles foram mais detalhados em levantamento de corpus e análise: o tutorial em vídeo e a entrevista de especialista.

${ }^{10}$ Amazon Sat (2012).

${ }^{11}$ TV Câmara São Paulo (2019)
} 


\begin{tabular}{c|c}
$\begin{array}{c}\text { Métodos de alfabetização (com Magda } \\
\text { Soares) }\end{array}$ & $\begin{array}{c}\text { A entrevista foi produzida pelo Canal Futura, numa série de entrevista sobre os desafios de ensinar } \\
\text { em suas múltiplas linguagens. }\end{array}$ \\
\hline $\begin{array}{c}\text { Pedagogia dos Multiletramentos (com } \\
\text { Roxane Rojo, professora da } \\
\text { UNICAMP) }\end{array}$ & $\begin{array}{c}\text { A entrevista foi produzida pelo programa Escrevendo o Futuro para o curso online Caminhos da } \\
\text { Escrita. Aborda a pedagogia dos multiletramentos e divulga diversas pesquisas e estudos relativos ao } \\
\text { tema. }\end{array}$ \\
\hline $\begin{array}{c}\text { As 10 competências gerais da BNCC: } \\
\text { como integrá-las no currículo (com } \\
\text { Anna Penido, do movimento pela } \\
\text { BNCC) }\end{array}$ & $\begin{array}{c}\text { A entrevista é veiculada pelo programa Autores da web, patrocinado pelas editoras Ática, Scipione e } \\
\text { Saraiva. O objetivo da entrevista é discutir alternativas para inserir as 10 competências gerais da } \\
\text { BNCC ao currículo escolar. }\end{array}$
\end{tabular}

Fonte: elaborado pelas autoras

Após esta breve contextualização, apresentamos, na seção seguinte, a modelização que, conforme explicado, usa os princípios teórico-metodológicos do ISD. Usamos quadros para facilitar a visualização, considerando a) contexto de circulação do gênero; b) construção composicional do gênero; e c) mecanismos textuais, enunciativos e estilo recorrentes.

\title{
6 OS DADOS: AS CONFIGURAÇÕES DA ENTREVISTA DE ESPECIALISTA
}

Nesta seção, apresentamos o modelo didático do gênero de entrevista de especialista, baseado no levantamento de dados das cinco entrevistas descritas na metodologia.

Quadro 2: Dados do contexto de circulação

\section{CONTEXTO DE CIRCULAÇÃO DO GÊNERO ENTREVISTA DE ESPECIALISTA}

\begin{abstract}
Esfera: divulgação e comunicação acadêmico-científica. O assunto a ser tratado é oriundo da esfera da pesquisa por se tratar da circulação de conhecimentos acadêmicos, conceitos e métodos, por exemplo, formulados por pesquisadores em relação às áreas em que atuam. O nível de abordagem sobre o assunto é mais ou menos aprofundado, dependendo do público; o entrevistado tem domínio sobre a temática sendo, na maioria das vezes, pesquisador da temática há muitos anos, o que o dá o status de especialista no assunto. Isto é percebido pelo fato de elas utilizarem expressões e jargões (termos técnicos) típicos da área em que atuam, com muita propriedade, além de fazerem apontamentos específicos sobre a área acadêmica enfocada.
\end{abstract}

Função social e objetivo: O objetivo é apresentar e divulgar uma temática, um conceito, um conhecimento gerado a partir de uma ou várias pesquisas, bem como debater e refletir sobre suas repercussões e resultados para a sociedade, na perspectiva dos especialistas de uma determinada área de estudos. As entrevistas podem ter o caráter tanto de comunicação, de interação com outro especialista, quanto de divulgação, para leigos, dada sua linguagem acessível, diferentemente do artigo, por exemplo, de caráter mais técnico e destinado para os próprios pares acadêmicos. Algumas características mais prototípicas de uma linguagem de divulgação científica serão apresentadas mais abaixo.

Interlocutores e papéis sociais: Os entrevistados são profissionais formados e atuantes em uma área específica de pesquisa, o que gera credibilidade nas informações dadas/debatidas. Os receptores das entrevistas podem ser os próprios pares, outros pesquisadores, público formado naquela determinada área, ou um interlocutor iniciante ou leigo na temática, que tenham interesse em aprender sobre

\footnotetext{
${ }^{12}$ Canal Futura (2013).

${ }^{13}$ Olimpiada Cenpec (2016).

${ }^{14}$ Autores na Web (2019).
} 
o assunto particular. Os entrevistadores são, na maioria das vezes, jornalistas ${ }^{15}$ das instituições dos canais citados na metodologia, geralmente especializados na temática; e os entrevistados são pesquisadores e docentes das áreas de Pedagogia e/ou Letras, no nosso corpus.

Conteúdo temático: Os temas tratados em entrevista com especialistas podem ser variados, mas todos têm caráter científico, porque abrangem conhecimentos gerados em pesquisas específicas das áreas em que os pesquisadores atuam. Com base nas entrevistas analisadas, o tema escolhido foi da área de Educação e da Linguística Aplicada, com subtópicos bastante específicos: multiletramentos, alfabetização, BNCC, estruturas físicas e pedagógicas de uma escola, etc.

Suporte, veiculação e canais: Em geral, os suportes são TV, rádio ou computador, páginas de internet e canais específicos (Youtube, Instagram, dentre outros). Especialmente os exemplares analisados, a entrevista é veiculada em canais televisivos (abertos ou fechados), transmitida em telejornais ou outras mídias, como canais do Youtube específicos de universidades, grupos de pesquisa ou outras instituições, com o suporte da internet. Neste último caso, o conteúdo fica acessível a qualquer pessoa com acesso à internet.

Momento de produção, circulação e consumo: As entrevistas podem ser transmitidas ao vivo (como é o caso do telejornal ou canais com uma programação ao vivo), ou de maneira assíncrona, disponibilizadas após a gravação. Pode também ser feita uma editoração da entrevista. Transmitida ao vivo, ou posteriormente à gravação, o interlocutor tem acesso à data em que a entrevista ocorreu. Especialmente nos canais de Youtube, a data de publicação da entrevista aparece logo abaixo do vídeo. Uma entrevista de especialista pode ocorrer quando um tema é novo na mídia e tem grande impacto na sociedade, como a BNCC, por exemplo, que gerou uma série de debates e produções, além das entrevistas.

Fonte: elaborado pelas autoras

Quadro 3: Dados da construção composicional

\section{CONSTRUÇÃO COMPOSICIONAL}

Modalidade: gênero multimodal, em que são integradas linguagem verbal e não verbal, oral e escrita: o verbal na modalidade oral é predominante; a modalidade escrita aparece na abertura, nos nomes de entrevistador e entrevistado, nome do canal, créditos etc.

Elementos não verbais: há música ambiente de fundo nas partes de início e fechamento da entrevista, bem como nos intervalos, se houver.

Gestos: entrevistador e entrevistado usam gestos com as mãos, muito comuns nas explicações; sinal de concordância ou discordância com a cabeça em vários momentos, quando o outro está falando.

Expressões faciais: as expressões faciais dependem do conteúdo (como por exemplo, se for abordado um problema grave, há expressões mais sérias; se for abordado um tema divertido, expressões de riso); também o tom mais ou menos formal e o tom mais ou menos descontraído podem alterar as expressões faciais dos interlocutores. Há enfoque da câmera no rosto do entrevistado. Os olhares dos entrevistados são voltados ora para o entrevistador, ora para a câmera, o que propicia um contato visual com o receptor

Observa-se também o balançar da cabeça, o mexer com as mãos e olhares atenciosos voltados para a câmera, por parte do entrevistado e do entrevistador.

\section{Posição dos locutores e ambiente:}

Disposição: entrevistado e entrevistador ficam assentados de frente um para o outro, em postura confortável; embora de frente um para o outro, podem se virar para olhar para a câmera. A caracterização dos participantes, em termos de vestimenta, é mais formal. Os cenários onde as entrevistas foram feitas são salas de estudos, bibliotecas ou estúdios. Neles, o receptor pode visualizar livros, estantes e prateleiras, ou seja, há uma ambientação que remete a estudos e pesquisas; a entrevista com especialista ainda pode ter um cenário mais formal em estúdio, isto é, com dispositivos tecnológicos (smart tv ao fundo), mesa com fichas e copos d'água, poltronas acolchoadas e microfone. Em canais televisivos, pode-se observar imagens de funcionários do programa ao fundo. Nesses casos, há uma iluminação adequada, com enfoque nos interagentes, bem como som adequado, sem interferências de barulhos externos.

Há uso de recursos típicos das interações orais, como marcadores conversacionais (claro! né? Bem), repetições, hesitações e correções. Há uso de estratégias de polidez positiva (“Estamos recebendo você, com muita honra e prazer”).

PLANO GERAL DO TEXTO: o gênero entrevista tem em geral três partes - abertura, desenvolvimento e fechamento.

\footnotetext{
${ }^{15} \mathrm{Em}$ três entrevistas do nosso corpus, os entrevistadores eram jornalistas; nas outras duas, as entrevistadoras são uma professora e uma assessora pedagógica (ambas de empresas privadas de educação - Instituto Singularidades e Somos Educação, respectivamente).
} 


\begin{abstract}
ABERTURA
- música de abertura;

- imagem (slide) multimodal com título da entrevista no plano de fundo (entrevista em canal educativo/institucional) - introdução ao assunto antes da apresentação do entrevistado, feita pelo entrevistador (com seu nome em legenda), para situar o interlocutor;

- breve apresentação do entrevistado pelo entrevistador; geralmente são citados o currículo do especialista, área de atuação, instituição, dentre outros;

- apresentação do objetivo da entrevista;

DESENVOLVIMENTO
\end{abstract}

O desenvolvimento é feito pelo "par" pergunta e resposta; a troca de turno é constante. As perguntas são previamente elaboradas pelo entrevistador/equipe, sendo as respostas dadas bastante objetivas, centradas na pesquisa e sem maiores comentários para além do que é perguntado, principalmente se houver pouco tempo disponível. Há a possibilidade de o entrevistador e o entrevistado complementarem verbalmente a informação do outro para endossarem seus pontos de vista, geralmente sem sobreposição de vozes ou disputa pelo turno, dado o caráter controlado do evento (HOFFNAGEL, 2003).

\title{
FECHAMENTO
}

- agradecimento formal do entrevistador ao entrevistado;

- despedida/agradecimento do entrevistado ao entrevistador/instituição e ao receptor;

- mensagem apelativa e direta do entrevistador ao receptor, para que este acompanhe outras partes desta entrevista ou assista as demais naquele canal;

- listagem de colaboradores/patrocinadores da entrevista ao final (pode ocorrer ao final do bloco, em caso de entrevista em canal educativo/instrucional).

\section{SEQUÊNCIAS TEXTUAIS OUTRAS FORMAS DE PLANIFICACÃO}

As entrevistas de especialistas são compostas por sequências descritivas e explicativas, típicas da linguagem acadêmico-científico, que apresenta os resultados de pesquisas e seus impactos para a sociedade, no nosso caso, as temáticas da educação. A sequência explicativa consiste em fazer asserções de conceitos, processos, resultados e transformá-los em conhecimento. Muito presente nos exemplares analisados, os entrevistados baseiam suas falas em conceitos mais específicos e se dispõem a explicá-los. A entrevista também se caracteriza pela sequência dialogal: há um diálogo entre o entrevistado e entrevistador, construído a partir da troca de turnos (em perguntas e respostas). A resposta do entrevistado pode ser complementada posteriormente em outro turno, a partir dos comentários ou observações feitas pelo entrevistador. Há um diálogo também entre entrevistador e os ouvintes, uma vez que o primeiro convida os expectadores a assistirem os demais blocos ou outras entrevistas, além de se remeter a perguntas e comentários dos ouvintes pelas redes sociais. O entrevistador agradece não só ao entrevistado, como também ao público. Há também trechos de sequência argumentativa, cujo objetivo é defender ponto de vista, quando principalmente, discutem-se os impactos das pesquisas na sociedade, por meio de uma atitude comunicativa, como é o caso das entrevistas selecionadas. Exemplo: “A Base é extremamente necessária, mas não é suficiente, uma vez que ela precisa de um trabalho de implementação nas escolas”.

TIPOS DE DISCURSO: predominantemente interativo e teórico.

Discurso interativo: implicado e conjunto - o emissor no mundo ordinário está implicado no mundo discursivo criado, e as coordenadas do mundo discursivo estão conjuntas ao mundo ordinário. As entrevistas analisadas são interações com emissão de termos que remetem aos agentes da interação, típicas da sequência dialogal. Exemplo como “de que modo você vê tal questão..." são comuns. Além disso, os interlocutores fazer referência a informações ancoradas em conhecimento explícito relacionado ao mundo discursivo do momento da fala.

Discurso teórico: autônomo e conjunto- o conteúdo temático organiza-se de acordo com as coordenadas do mundo discursivo do agente produtor; nenhuma unidade linguística refere-se aos interagentes, havendo autonomia em relação aos parâmetros da ação de linguagem em curso. O discurso teórico é típico da linguagem científica, porque enfoca os objetos em uma linguagem desprovida de elementos espaço-temporais ou referências aos agentes produtores, como "a alfabetização é um processo..."; “a multimodalidade caracteriza-se por....”, ou seja, são feitas referências aos conceitos e explicações dos fenômenos estudados na área.

Fonte: elaborado pelas autoras 
Quadro 4: Dados dos mecanismos textuais, enunciativos e estilo

\section{MECANISMOS TEXTUAIS, ENUNCIATIVOS E ESTILO RECORRENTES}

Coesão verbal: percebe-se, em grande medida, nas entrevistas analisadas, o uso do presente do indicativo, relacionado a fatos, verdades e saberes legitimados. Exemplos: "estas SÃO competências que você aprende vivenciando", “a criança APRENDE”, "Ninguém NEGA".

O pretérito também é empregado em momentos nos quais os especialistas fazem explicações fazendo contrapontos com informações e conceitos já elaborados em outra época, com o intuito de fazer reflexões e comparações com o momento atual. Exemplo: "Quando o conceito aparece, os autores defendiam (...)", "Nos EUA, o debate foi tão intenso na década de 60 (...)”, "A escola pública, a partir dos anos 70, teve uma série de mudanças”.

Coesão nominal: há recorrentes referenciações nas entrevistas para introduzirem temas, conceitos e pessoas. Para isso, são utilizados pronomes pessoais e possesivos (ela, ele, sua), sinonímia e hiperonímia (ensino e processos de escolarização; instituições escolares e escolas; imagens, infográficos e mapas; novas tecnologias, livros digitais e interativos). Há uso recorrente de pronomes pessoais e possessivos no plural com verbos para endossar o ponto vista particular do especialista sobre uma dada questão (“Se a gente começa a avaliar o aluno", “Temos que pensar algumas práticas, senão isso tudo será inócuo”, "na minha concepção”).

Características dos períodos e organizadores textuais: os períodos são compostos por segmentos longos, devido à preocupação do entrevistador em fazer contextualizações e comentários sobre o assunto abordado, além de explicações dos diferentes conceitos e abordagens. São comuns organizadores textuais de explicação (porque, por isso, neste caso); de conclusão (enfim, então); de organização e sequenciação das informações (não só, mas também, de um lado, de outro, por isso, primeiro, segundo; segunda questão); de tempo (antes, depois, agora, no século passado), dentre outros.

Vozes sociais: As vozes dos autores, entrevistador e entrevistado, se mesclam a diferentes vozes sociais, para reforçar pontos de vista e trazer explicações, quando se faz menções aos conceitos, fundamentos e correntes teóricas, bem como a instituições a que pertencem os pesquisadores da área específica. Termos que correspondem a linhas teóricas, como "o Grupo de Nova Londres", determinadas instituições e centros de pesquisa contribuem para agregar valor à entrevista.

Modalizadores: quando se abordam temáticas relativas à educação, como nas entrevistas analisadas, são comuns modalizadores lógicos cujos fatos relatados são aceitos como "verdades" coletivamente, como a ideia de que a educação traz benefícios para a população. Também são atestados modalizadores deônticos, de avaliações sociais mais amplas, e apreciativos, de avaliação mais particular do emissor para demarcar opinião do entrevistado acerca do tema. São utilizados trechos como "É preciso investir", "efetivamente atendem", "talvez", "normalmente", "infelizmente" dentre outros.

Estilo: a linguagem utilizada na entrevista com especialista é marcadamente formal, tendo termos técnicos permeando toda a interação, uma marca do discurso acadêmico-científico. A partir do corpus analisado, tanto o entrevistador quanto o entrevistado utilizam termos técnicos e conceitos específicos da área problematizada. Apesar disso, o entrevistador faz uma contextualização do assunto antes de fazer as perguntas, estratégia esta que situa os ouvintes no assunto. O entrevistado geralmente explica conceitos mais específicos para expor seu ponto de vista e tratar das implicações da temática abordada.

\section{Outros aspectos linguísticos:}

A credibilidade da informação se dá por várias razões: são canais especializados (Canal Futura), com patrocinadores (Fundação Itaú Social), além do currículo do entrevistado e seu papel social, da universidade ou laboratório de pesquisa ("Magda Soares uma das maiores especialistas em alfabetização no país). As escolhas lexicais feitas pelos participantes se ancoram na esfera científica, envolvendo as pesquisas, as teorias e os métodos. Desta forma, pode-se dizer que a entrevista com especialistas propicia uma difusão de saberes sistematizados e legitimados. Assim, há uso de uma linguagem clara e objetiva, atendendo ao uso da norma culta língua portuguesa. Por se tratar de discurso dessa esfera, há uma omissão dos agentes da ação (É preciso fazer uma parceria ..., Não se pode falar em método, mas em métodos...) e uso de vocabulário técnico, próprio da área de educação (ambiente letrado, processos avaliativos, fundamentos linguísticos, grafia). Como se trata de difusão do conhecimento, que também atinge a população em geral, e não somente os pares acadêmicos (outros cientistas), há uma série de elementos didatizantes e metáforas, que são típicas do discurso científico. A função desses elementos é explicar fenômenos desconhecidos, por meio de definições, analogias, exemplificações e paráfrases.

Fonte: elaborado pelas autoras 
A proposta de fazer um levantamento das configurações dos gêneros condiz com a ideia de Rinck, Silva e Assis (2012) que reforçam que, quando transpostos para o ensino, os gêneros devem ser compreendidos como formas de agir. Isso significa que, como artefatos simbólicos de mediação que se encontram momentaneamente estabilizados pelo uso, é preciso ressaltar suas relações com o contexto social e cultural mais amplo, sendo necessário, por isso, uma vivência em experiências situadas. "Os gêneros não podem nunca ser objeto de uma classificação racional, estável e definitiva” (BRONCKART, 1999, p. 138). Como os docentes e graduando estavam inseridos numa atividade de apropriação de conhecimento, pensamos que a interação com o conhecimento científico deveria se dar não apenas como a leitura de artigos científicos, mas também com os gêneros orais acadêmicos. Como as entrevistas são dinâmicas, e com a mediação síncrona das formadoras, foi possível fazer uma avaliação positiva dessa proposta.

A modelização da entrevista de especialista foi base para que os docentes e graduandos não só construíssem um material didático a ser usado com seus próprios alunos, mas também produzissem entrevistas com especialistas, uma experiência desafiadora e interessante, segundo os participantes. Após a produção, desenvolvemos uma reflexão sobre a produção de gêneros orais em cursos de formação inicial ou continuada. O resultado demostrou que tal atividade não é comum nesses cursos. Ademais, a experiência de produzir uma entrevista com alguns especialistas brasileiros ${ }^{16}$ foi extremamente relevante para os participantes, que se sentiram altamente valorizados por poderem interagir com pesquisadores de reconhecimento nacional na área da Linguística Aplicada e da Educação e contribuir com a construção do conhecimento na área.

\section{CONSIDERAÇÕES FINAIS}

Neste trabalho, objetivamos apresentar a modelização da entrevista de especialista, que subsidiou um trabalho de construção de materiais e de produção de gêneros orais em contexto de letramento acadêmico. Almejamos ampliar as investigações que tematizam a oralidade em práticas de linguagem da esfera acadêmica e inserir outras propostas na construção de conhecimento por professores. Para além de artigos, capítulos de livros, demais materiais escritos e da própria interação na sala de aula, é preciso ampliar a interação dos graduandos e docentes com o conhecimento que circula pela oralidade, e os canais aqui levantados constituem-se como material frutífero para a apropriação do conhecimento.

Na discussão sobre formação docente para o trabalho com a oralidade, entendemos que, como muitos professores ainda não desenvolvem práticas efetivas, é necessário reforçar o óbvio: ampliar o escopo de trabalho na temática, envolvendo tanto cursos de formação inicial e continuada quanto pesquisas intervencionistas, que propiciem aos docentes refletir sobre novas possibilidades de trabalho. A falta de sistematização dos gêneros e de bases teóricas e metodológicas contundentes, além da falta de experiências efetivas de autoria, faz com que o professor em formação não tenha segurança para desenvolver uma prática pedagógica produtiva, que o impede de realizar uma transposição relevante que ultrapasse a descrição dos textos, mas que efetivamente possibilite aos alunos agir pela linguagem.

\section{REFERENCIAS}

ABREU-TARDELLI, L. S.; VOLTERO, K.M. O papel da ficha de avaliação e da escuta no ensino do gênero seminário. Revista Entretextos, Londrina, v. 19, n.1, p. 13-42, 2019.

ALBAGLI, S. Divulgação científica: informação científica para a cidadania? Ci. Inf., Brasília, v. 25, n. 3, p. 396-404, set./dez. 1996.

\footnotetext{
${ }^{16}$ As entrevistas foram feitas com Clécio Bunzen (UFPE), Carla Coscarelli (UFMG), Ana Elisa Ribeiro (CEFT-MG), Adriana Fischer (FURB), Talita C. Marine (UFU), Eliane Borges C. Albuquerque (UFPE) e José Ribamar L. Batista Júnior (UFPI) e abordaram temáticas como oralidade, letramento acadêmico, ensino de literatura, tecnologias no ensino, alfabetização, rádio escolar e ensino de língua portuguesa. Elas estão disponíveis na página do Grupo de Pesquisa Linguagem, Ensino e Práticas sociais do Facebook. Essas entrevistas não foram base para a produção do MDG, conforme explicado na seção de dados.
} 
ALVIM, V. T.; MAGALHÃES T. G. Oralidade na escola: A “escuta ativa” como procedimento didático no ensino de Língua Portuguesa nos anos iniciais do ensino fundamental. In: BARROS, E. M. D. et al. Propostas didáticas para o ensino de Língua Portuguesa. 2018. p. 113-134.

ARAÚJO, D. L.; SILVA, W. M. Oralidade em foco: conceito, descrição e experiências de ensino. Editora Pontes, 2016.

BARBOSA, B.; LOPES, I. A. A entrevista oral produzida por alunos de $8^{\circ}$ ano do Ensino Fundamental: aspectos formais e funcionais. Revista Letras e Letras, Uberlândia, v. 32, n. 4, p. 88-113, 2016.

BAKHTIN, M. Estética da criação verbal. São Paulo: Martins Fontes, 2003.

BALTAR, M. Rádio escolar: uma experiência de letramento midiático. São Paulo: Cortez editora, 2012.

BAUMGÄRTNER, C. T. Grupos de estudos em Língua portuguesa - GELP: uma experiência de formação continuada de professores com foco em gêneros orais e ensino. In: BUENO, L. COSTA-HÜBES, T. C. Gêneros orais no ensino. Campinas - SP: Mercado de Letras, 2015. p. 91-116.

BRONCKART, J. P. Atividades de linguagem, textos e discursos: por um interacionismo sociodiscursivo. Trad. Anna Rachel Machado e Péricles Cunha. 2. ed. São Paulo: EDUC, 1999.

BRONCKART, J. P. Atividade de linguagem, discurso e desenvolvimento humano. Trad. Anna Raquel Machado e Maria de Lourdes Meirelles Matencio. Campinas/SP: Mercado de Letras, 2006.

BUENO, L. Gêneros orais na escola: necessidades e dificuldades de um trabalho efetivo. Revista Instrumento, v. 11, n. 1, p. 9-18, 2009.

BUENO, L.; COSTA-HÜBES, T. C. Gêneros orais no ensino. Campinas: Mercado de Letras, 2015.

CARNIN, A. Sobre interação e intervenção formativas em contexto de desenvolvimento profissional docente: reflexões em curso. In: GUIMARÃES, A. M. M.; CARNIN, A.; LOUSADA, E. G. (org.). O Interacionismo Sociodiscursivo em foco: reflexões sobre uma teoria em contínua construção e uma práxis em movimento. Araraquara: Letraria, 2020. p. 42-71.

CARNIN, A.; GUIMARÃES, A.M.M. Modelo didático de gênero, genericidade e textualidade: apontamentos sobre o ensino de língua portuguesa e a formação de professores. In: WITTKE, C. I.; MORETTO, M.; CORDEIRO, G. S. Dilemas e perspectivas didáticas em formação docente e ensino de língua. Campinas, SP: Mercado de Letras, 2018. p. 49-77.

COSTA, K. R.; PAZ, A. M. O. Letramento profissional: estudos em perspectivas. Revista do GELNE, v.19, n. Especial, 2017.

COSTA-HÜBES, T. C. SWIDERSKI, R. M. S. Gêneros orais e ensino: uma experiência didática com notícia televisiva. In: BUENO, L.; COSTA-HÜBES, T. C. (org.). Gêneros orais no ensino. Campinas, SP: Mercado de Letras, 2015. p. 139-168.

DE PIETRO, J. F.; SCHNEUWLY, B. O modelo didático do gênero: um conceito da engenharia didática. In: NASCIMENTO, Elvira Lopes. 2.ed. Gêneros textuais: da didática das línguas aos objetos de ensino. Campinas: Pontes, 2014. p.51-81.

DOLZ, J.; NOVERRAZ, M.; SCHNEUWLY, B. Sequências didáticas para o oral e a escrita: apresentação de um procedimento. In: SCHNEUWLY, B.; DOLZ, J. Gêneros orais e escritos na escola. Campinas, SP: Mercado de Letras, 2004. p. 95-128. 
DOLZ, J.; SILVA-HARDMEYER, C.; COPPOLA, A. Análise de dois dispositivos de formação docente em didática do oral. In: MORETTO, M.; WITTKE, C. I.; CORDEIRO, G. S. (org.). Dialogando sobre (trans)formações docentes: (dis)cursos sobre a formação inicial e continuada. Campinas, SP: Mercado de Letras, 2018. p. 229-258.

FÁVERO, L. L. A entrevista na fala e na escrita. In: PRETI, D. (org.). Fala e escrita em questão. São Paulo: Humanitas; FFLCH/USP, 2000. p.79-98.

FÁVERO, L. L.; ANDRADE, M. L. C. V. O.; AQUINO, Z. G. O. Oralidade e escrita: perspectivas para o ensino de língua materna. 5 ed. São Paulo: Cortez, 2005.

FELIX, S.; BARROS, E. M. D. A apropriação do gênero "entrevista": a retextualização fala/escrita e o processo de letramento. Secretaria de Educação. Governo do Estado do Paraná. 2012. Disponível em: http://www.diaadiaeducacao.pr.gov.br/portals/cadernospde/pdebusca/producoes pde/2012/2012 uenp port artigo samara fe lix.pdf. Acesso em: 20 mar. 2019.

FIAD, R. S. Algumas considerações sobre os letramentos acadêmicos no contexto brasileiro. Pensares em Revista, São Gonçalo-RJ, n. 6, p. 23-34, jan./jun. 2015.

GATTI, B. A. et al. Professores do Brasil: novos cenários de formação. Brasília: UNESCO, 2019.

GUEDES-PINTO, A. L. Práticas de escrita no ensino universitário e suas relações com a formação docente. Revista Scripta, Belo Horizonte, v. 16, n. 30, p. 137-149, 2012.

GUIMARÃES, A. M. M.; CARNIN, A.; BICALHO, D. C. (org.). Formação e trabalho docente: múltiplos olhares para o ensino de língua materna. Campinas, SP: Editora Pontes, 2016.

GUIMARÃES, A. M. M.; SOUZA, J. Quão interacional é a oralidade que ensinamos na escola. In: MAGALHÃES, T. G.; CRISTOVÃO, V. L. L. (org.). Oralidade e ensino de Lingua Portuguesa. Campinas: Editora Pontes, 2018. p. 75-99.

HOFFNAGEL, J. C. Entrevista: uma conversa controlada. In: DIONISIO, A. P.; MACHADO, A. R. (org.). Gêneros textuais e ensino. Rio de Janeiro: Lucerna, 2003. p. 180-193.

LEAL, T. F; GOIS, S. A oralidade na escola: a investigação do trabalho docente como foco de reflexão. Belo Horizonte: Autêntica, 2012.

LOPES, M. A. P. T. Gêneros do discurso na formação: saberes em diálogo na constituição da identidade acadêmica e profissional. In: REICHMANN, C. L.; GUEDES-PINTO, A. L. Horizontes (im)possíveis no estágio: práticas de letramento e formação de professores de línguas. Campinas, SP: Editora Pontes, 2018. p. 195-218

LOPES, M. A. P. T.; RINCK, F. Formar pela escrita e para a escrita - olhares sobre a formação e os futuros professores. Revista Scripta. v. 23, n. $48,2019$.

LUNA, E. A. A. Desafios de docentes universitários brasileiros sobre didática da oralidade na formação do professor de Português. Indagatio Didactica, v. 9, p. 81-96, 2017.

MACHADO, A. R.; CRISTOVÃO, V. L. L. A construção de modelos didáticos de gêneros: aportes e questionamentos para o ensino de gêneros. Linguagem em (Dis)curso, v. 6, p. 547-573, set./dez 2006. 
MACHADO, A. R.; LOUSADA, E.; FERREIRA, A. D. O professor e seu trabalho: a linguagem revelando práticas docentes. Campinas, Mercado de Letras, 2011.

MARCUSCHI, L. A. Concepção de língua falada nos manuais de português de $1^{\circ} \mathrm{e} 2^{\circ}$ graus: uma visão crítica. REUNIÃO ANUAL DA SBPC. Belo Horizonte, 1997 (mimeo).

MARCUSCHI, L. A. Da fala para a escrita: atividades de retextualização. São Paulo: Cortez, 2001.

MARCUSCHI, L. A. Produção textual, análise de gêneros e compreensão. São Paulo: Parábola, 2008.

MAGALHÃES, I. Letramento, intertextualidade e prática social crítica. In: MAGALHÃES, I. (org). Discursos e práticas de letramento: pesquisa etnográfica e formação de professores. Campinas, SP: Mercado de Letras, 2012. p. 17-68.

MAGALHÃES, T. G. Oralidade nas dissertações do Mestrado Profissional em Letras: formação docente para possibilidades de inovação na escola básica. Revista da Anpoll, v. 51, p. 71-88, 2020.

MAGALHÃES, T. G. Oralidade e ensino de Língua Portuguesa no Brasil: uma leitura. In: MAGALHÃES, T. G.; CRISTOVÃO, V. L. L. Oralidade e ensino de Língua Portuguesa. Campinas, SP: Editora Pontes, 2018. p.15-38.

MAGALHÃES, T. G.; BARBOSA, G. O. O gênero entrevista: uma experiência de transposição didática no Ensino Fundamental. In: BARROS, E. M. D.; STORTO, L. J. (org.). Gêneros do jornal e ensino: práticas de letramentos na contemporaneidade. Campinas: Pontes, 2017. p.95-118.

MAgAlHÃES, T. G.; CRISTOVÃO, V L L. (org.). Oralidade e ensino de Língua Portuguesa. Campinas, SP: Editora Pontes, 2018.

MAGAlHÃES, T. G.; CALLIAN, G. R.; CABETTE, P. S. L. Gêneros de texto da prática profissional docente: primeiras reflexões sobre as demandas do trabalho. Revista Virtual de Estudos da Linguagem, edição especial, v. 18, n. 17, p. 209-245, 2020.

MORATTO, J. STORTO, L. J. Ensino da oralidade por meio do gênero textual/discursivo entrevista de seleção: relato da implementação de uma sequência de atividades. Revista Signum: Estudos da Linguagem, Londrina, v. 22, n. 1, p. 114-140, abr. 2019.

OLIVEIRA, P. T. C.; COSTA-MACIEL, D. A. G. Operadores argumentativos no contexto do debate regrado: escutando o docente a respeito das propostas de ensino presentes no livro didático. In: MAGALHÃES, T. G.; CRISTOVÃO, V. L. L. (org.). Oralidade e ensino de Língua Portuguesa. Campinas: Editora Pontes, 2018. p.119-140.

RINCK, F.; SILVA, J. Q.; ASSIS, J. Qual abordagem erigir para pensar as práticas de leitura e escrita na formação acadêmica e/ou na vida profissional? Revista Scripta, v. 16, n. 30, p. 7-15, 2012.

ROJO, R.; SCHNEUWLY, B. As relações oral/escrita nos gêneros orais formais e públicos: o caso da conferência acadêmica. Linguagem em (Dis)curso, Tubarão, v. 6, n. 3, p. 463-493, set./dez. 2006.

SCHNEIDER, L. J. Oralidade e ensino na formação de professores: resultados de um percurso formativo. In: MAGALHÃES, T. G.; FERREIRA, C. S. Oralidade, formação docente e ensino de língua portuguesa. Araraquara: Letraria, 2019. p. 121-139. 
SCHNEUWLY, B.; DOLZ, J. Gêneros orais e escritos na escola. Campinas: Mercado de Letras, 2004.

SITRI, F.; RINCK, F. Por uma formação linguística para os textos profissionais. In: RINCK, F; BOCH, F; ASSIS, J. A. (org.). Letramento e formação universitária: formar para a escrita e pela escrita. Campinas: Mercado de Letras, 2015. p. 455-476.

SOUZA, K. A.; CRISTOVÃO, V.L.L. O gênero textual "entrevista de emprego": suas características na esfera acadêmica visando escola de idiomas. In: BUENO, L.; COSTA-HÜBES, T. C. (org.). Gêneros orais no ensino. Campinas, SP: Mercado de Letras, 2015. p. 229-276.

STREET, B. Letramentos sociais: abordagens críticas do letramento no desenvolvimento, na etnografia e na educação. Trad. Marcos Bagno. São Paulo: Parábola, 2014.

STRUKOSK, E. E. C. P.; BIAZI, T. M. D.; STUTZ, L. Modelo didático do gênero digital HQtrônicasWatchmenmotion comic. Veredas Revista de Estudos Linguísticos, especial Interacionismo Sociodiscursivo, v. 21, n. 3, 2017.

VIANNA, C. A. D. et al. Do letramento aos letramentos: desafios na aproximação entre letramento acadêmico e letramento do professor. In: KLEIMAN, A. B.; ASSIS, J. A. Significados e ressignificações do letramento. Campinas, SP: Mercado de Letras, 2016. p. 27-59.

ZANI, J. B.; BUENO, L. O ISD, a análise da conversação e os meios não-linguísticos: uma proposta de quadro de análise da comunicação oral em eventos científicos. Revista Veredas de Estudos Linguísticos, especial Interacionismo Sociodiscursivo, v. 21 , n. 3, p. 615-640, 2017.

\section{Entrevistas analisadas:}

AMAZON Sat: Entrevista com especialista em educação sobre como avaliar estrutura de uma boa escola. Amazon Sat. Youtube. 31 de dezembro de 2012.7min. Disponível em: https://www.youtube.com/watch?v=8zFQJQjEzPg. Acesso em: 24 ago. 2020.

AUTORES na web: As 10 competências gerais da BNCC (Bloco 1): Como integrá-las ao currículo. Autores na web. Youtube. 08 de maio 2019.10min28s. Disponível em: https://www.youtube.com/watch?v=MCobuw8xYo8. Acesso em: 24 ago. 2020

CANAL Futura: Métodos de alfabetização - Magda Soares - Entrevista - Canal Futura. Canal Futura. Youtube. 18 de julho de 2013.15min22s. Disponível em: https://www.youtube.com/watch?v=mAOXxBRaMSY. Acesso em: 24 ago. 2020.

OLIMPIADA Cenpec: Pedagogia dos Multiletramentos. Roxane Rojo - Parte 1. Olimpíada Cenpec. Youtube. 14 de julho de 2016. 13min46s. Disponível em: https://www.youtube.com/watch?v=IRFrh3z5T5w. Acesso em: 24 ago. 2020.

TV CÂMARA São Paulo: Especialista fala sobre Base Nacional Comum Curricular.

Tv Câmara São Paulo. Youtube. Ano: 2019. 8min2s. Disponível em: https://www.youtube.com/watch?v=coD8ifWAw78. Acesso em: 24 ago. 2020

\section{(๑) $\circledast \Theta$}

Recebido em 17/01/2021. Aceito em 16/03/2021. 